\title{
ETIMOLOGÍAS DEL ESPAÑOL DE COSTA RICA
}

\author{
Etymologies of spanish in Costa Rica
}

Mario Portilla*

\section{RESUMEN}

En este trabajo se propone una caracterización de las etimologías de los costarriqueños recogidos en distintos diccionarios publicados. También, se ilustra con ejemplos la microestructura de las entradas de un diccionario etimológico del español de Costa Rica que se encuentra en progreso. Finalmente, se muestran las proporciones de las contribuciones léxicas aportadas por las distintas lenguas que dan origen a los costarriqueñismos. Palabras clave: costarriqueñismos, etimología, lexicografía.

\begin{abstract}
In this article, a typology of the costarriqueñismos (peculiar words used in Costa Rica) founded in different published dictionaries is proposed. Besides, the format of the entries for an etymological dictionary of Costa Rican Spanish in progress is illustrated with examples. Finally, the proportions of the lexical contributions for the costarriqueñismos according to the donor language are shown.
\end{abstract}

Key Words: costarriqueñismo, etymology, lexicography. 
Dice un proverbio que las cosas bellas son difíciles de saber; y ciertamente, la ciencia de los nombres no es trabajo ligero.

Platón, Cratilo

El estudio etimológico es de larga data en la tradición de las investigaciones lingüísticas en Occidente. La ciencia etimológica surge en el contexto de la polémica de los gramáticos griegos acerca de la naturaleza del lenguaje. Los partidarios de la idea de que las formas lingüísticas no son arbitrarias, sino motivadas, encuentran en la investigación del origen de las palabras una prueba de su parecer.

El significado del vocablo etimología declara el objetivo original de la disciplina de esclarecer lo verdadero, el origen auténtico que hay detrás de las formas de las palabras, el étymos. Para decirlo con palabras del gramático griego Melampo: "Etimología es la desmembración de las palabras, mediante la cual se aclara la verdad; étimon, en efecto, se llama lo verdadero."

Por supuesto, la investigación etimológica es tan antigua en el ámbito del español a como lo son los estudios de gramática y lexicografía. Antonio de Nebrija, en la enumeración de las partes que componen su Gramática de la Lengua Castellana de 1492 dice: "La tercera los griegos llamaron etimología. Tulio interpretola anotación. Nosotros podemos la nombrar verdad de las palabras." En esta parte, Nebrija estudia la forma y el significado de las llamadas partes de la oración o clases de palabras. Su trabajo, sin embargo, estaba más orientado a la descripción morfológica que a la investigación semántica o propiamente etimológica.

El Tesoro de la Lengua Castellana de Sebastián de Covarrubias (1611), el primer diccionario monolingüe español, contiene referencias etimológicas para gran parte de los vocablos que constituyen las entradas. Igualmente, sucede con el Diccionario de Autoridades de la Real Academia Española (1726-1739), que estuvo basado, en buena medida, en el diccionario de Covarrubias.
Los diccionarios contrastivos del español, los generales de americanismos o los de regionalismos particulares, sin embargo, no han sido consistentes en la tarea de señalar etimologías. Por ejemplo, los primeros diccionarios de americanismos, el Diccionario de voces americanas atribuido a Manuel José de Ayala, redactado entre 1750 y 1777, y el Diccionario histórico geográfico de las Indias Occidentales ó América de Antonio de Alcedo, publicado entre 1786 y 1789, no contienen etimologías de los vocablos recogidos.

Lo mismo sucede con muchos diccionarios de regionalismos tanto americanos como peninsulares. Ni el primer diccionario de 'provincialismos' americanos, el Diccionario provincial de voces cubanas de Esteban Pichardo, publicado en 1836, ni el Ensayo de un diccionario aragonés-castellano de Pedro José Gelabert, publicado en 1853, por ejemplo, presentan referencias etimológicas en las entradas comprendidas en ellos.

Sin embargo, otros diccionarios de regionalismos americanos sí hacen algunas referencias al origen de las palabras tratadas. Tal es el caso de la obra Vicios del lenguaje $y$ provincialismos de Guatemala de Antonio Batres Jáuregui, de 1892, y el Diccionario de barbarismos y provincialismos de Carlos Gagini, de 1893. Sin embargo, las referencias etimológicas son muy escasas, se presentan asistemáticamente y corresponden más bien a información de tipo enciclopédico.

Un ejemplo tomado de la obra de Antonio Batres es el siguiente:

Amol. Es una planta venenosa, que se usa para pescar, y que mata todos los peces grandes y chicos [...] En lengua mexicana se llama ese tósigo AMOLE, nombre que se conservó hasta el siglo XVII. (pp. 90-1)

Otro ejemplo extraído esta vez del Diccionario de Gagini es el siguiente:

Achará. Ignoramos el origen de esta expresiva interjección costarricense, equivalente en castellano à ¡qué lástima! ¿Tendrá relación con el verbo andaluz hacharar? (p. 19) 
En ningún caso, es la intención de los autores establecer de manera sistemática las etimologías de los vocablos que presentan. Las referencias etimológicas aparecen casi como una acotación histórica o etnográfica. Así, por ejemplo, en la entrada correspondiente al lema adifesio Gagini refiere distintas historias que explicarían la causa que lleva al sentido de 'despropósito' o 'cosa ridícula' que tiene el vocablo en su forma estándar adefesio, según varias fuentes. Sin embargo, al final declara a modo de disculpa: "Todo esto es para nosotros hablar ad ephesios, pues aquí no nos compete inquirir el origen del vocablo: solamente queríamos insinuar que no se dice adifesio sino adefesio."

Finalmente, otra cita ejemplifica el valor histórico-etnográfico de las referencias etimológicas en esta obra de Gagini.

\begin{abstract}
Agora. Burlábase de nuestros labriegos un extranjero petulante porque dicen agora en lugar de ahora: según él, era ésta una de las más graciosas corruptelas que había oído en Costa Rica; pero el pobre se quedó como quien ve visiones cuando le mostramos los siguientes versos de Garcilaso: 'Do están agora aquellos claros ojos/ que llevaban tras sí como colgada/ mi ánima doquier que se volvían?' Agora (del latín hac hora, en esta hora) es una palabra castellana que se arrumbó en el siglo pasado. Todavía es de uso común entre los campesinos españoles. (p. 24)
\end{abstract}

Tanto en el Diccionario de costarriqueñismos de Carlos Gigini, publicado en 1918, como en el Arturo Agüero publicado en 1996, pero iniciado a principios de los años cincuenta, presentan anotaciones etimológicas solo para una minoría de los lemas incluidos en cada obra. Sobre todo, ambos autores proporcionan información etimológica de los vocablos cuando se trata de préstamos de otras lenguas.

En el prólogo de su Diccionario de costarriqueñismos Gagini señala:

Con respecto al origen de las voces y expresiones de nuestro lenguaje hay que advertir: [...] Que siendo Costa Rica el punto de confluencia de las corrientes migratorias del Norte y el Sur de Nuestro Continente, los vocablos indígenas son de tan diversa procedencia, que la investigación de su etimología y filiación étnica ha sido necesariamente la parte más ardua y menos fructuosa de mi labor (p. xxxi).

En sus "Consideraciones y notas preliminares sobre el léxico del español de Costa Rica", especie de prólogo a su diccionario, Arturo Agüero declara explícitamente las razones tanto para incluir referencias etimológicas para algunos términos como aquellas para no hacerlo en otros casos:

Sobre la etimología. El campo de la etimología siempre ha sido inseguro y resbaladizo. Por este motivo no se han parado mientes en averiguar la de algunas palabras que la mantienen obscura. Desde luego pudo haberse indicado la que ofrece un buen diccionario etimológico, o la del mismo Diccionario académico, pero esto sería innecesario y ocioso teniendo el consultante a su disposición las fuentes de consulta pertinentes. Solo en alguna voz indígena, particularmente de Costa Rica, se ha procurado averiguar su verdadero étimo, pero con las debidas reservas. Excepcionalmente se aclaró la etimología de canfín, y se corrigió, pero cuando se tuvo duda, el étimo posible se colocó entre signos de interrogación, o escribiendo la frase dubitativa “tal vez de..." antes de él. (p. xvi)

Aunque es muy interesante describir los casos en que los autores mencionados anotan referencias etimológicas y su presentación o contenido, dejaremos para otro momento este análisis.

Por otra parte, el Nuevo diccionario de costarriqueñismos de Miguel Ángel Quesada Pacheco (cuya primera edición es de 1991 y su cuarta de 2007) y el Diccionario de costarriqueñismos de Víctor Sánchez y su equipo de colaboradores (en elaboración) generalmente no presentan información de tipo etimológico en sus entradas.

Quesada Pacheco solo de manera muy excepcional consigna información de esta naturaleza, como en el caso de la palabra eclipse.

Eclipse. 'Mancha rojiza y a veces vellosa en la piel'. (Se llama así porque según la creencia popular, la madre de la persona que tiene dicha mancha estuvo, durante el embarazo, expuesta a un eclipse).

Por su parte, Sánchez (manuscrito inédito, comunicación personal) presenta observaciones etimológicas solo cuando se trata de formas 
anglicadas o galicadas, como en el caso del término aplicación.

\begin{abstract}
Aplicación $f \mathbf{1}$ En corte y confección, adorno bordado o de encaje que se le pone a una prenda. Los vestidos pomposos, con caídas suaves y aplicaciones doradas fueron la propuesta del diseñador Stephane Rolland. 2 Formulario mediante el cual se solicita algo. Llene una aplicación preliminar en línea o llame al (..) para solicitar una aplicación y recibir más información. Obs: Es anglicismo de application.
\end{abstract}

En su Diccionario histórico del español de Costa Rica, de 1995, Miguel Ángel Quesada Pacheco también solo raramente incluye referencias al origen de algunos términos, como por ejemplo tico, que determina como el resultado de una aféresis del vocablo hermanitico.

Modernamente, tanto los diccionarios generales de americanismos como los particulares de los distintos países, al decantarse más exclusivamente por la corriente sincrónica, no suelen ofrecer información etimológica. Este hecho es confirmado por Milagros AlezaIzquierdo (2000: 36-7), por ejemplo, para varios diccionarios de americanismos publicados en la década de los noventa del siglo pasado.

Una de las novedades que presentan estos diccionarios es la de no incluir indicaciones sobre el origen de las palabras, dado el caos que en la lexicografía tradicional ha producido el intento de indicar el origen, sobre todo, de aquellas voces que no son españolas (aunque el origen latino, griego y árabe también se solía marcar). Ninguno de los diccionarios que estamos revisando (NDA, DHAV, NDC) incluye etimología ni información sobre el origen del lema.

A pesar de esto, el Diccionario de americanismos de la Asociación de Academias de la Lengua Española, publicado en 2010, presenta etimologías para los vocablos de manera selectiva. En la "Guía del consultor" se indica lo siguiente acerca de la información etimológica contenida en el diccionario:

Llevan información etimológica los lemas que la necesiten para su mejor comprensión, sobre todo los que no sean de procedencia patrimonial española (p. xl).
El panorama anterior muestra de forma evidente que existe un campo abierto para la indagación etimológica del español de Costa Rica. Consideramos que es necesario contar con un diccionario que recoja las etimologías de los vocablos regionales que, por contraste con el español general, son denominados costarriqueñismos.

Actualmente, este trabajo se halla en proceso y forma parte de un proyecto mayor de investigación etimológica del español. En una segunda etapa, esta obra pretende abarcar el ámbito completo del español de Centroamérica. Finalmente, en una tercera etapa, comprenderá el estudio etimológico de los llamados americanismos.

A continuación se presenta una tipología de los vocablos que han sido incluidos en los diccionarios con una marca de costarriqueñismo, de acuerdo con sus características etimológicas.

El primer tipo de voces está constituido por aquellas palabras no derivadas, las llamadas primitivas o simples y las compuestas, las cuales difieren del uso de general por presentar una acepción particular distinta, pero cuyas formas son idénticas en el español general.

Pareciera que, en muchos casos, la anotación etimológica sea innecesaria, pues, como dijo Arturo Aguero, otras fuentes pueden dar perfecta cuenta de su origen. Sin embargo, no pocas veces vale la pena incluir información enciclopédica que explique el origen del significado del uso regional del término.

Algunos ejemplos de esta categoría de términos son los siguientes:

Boca. 'Bocadillo servido como acompañamiento de una bebida; alimento ligero que se toma antes de las comidas como aperitivo': aféresis de abreboca 'alimento ligero que se toma antes de las comidas como aperitivo', de abrir + boca 'abertura anterior por la que se ingieren los alimentos', del latín bucca 'boca, originalmente mejilla'.

Plátano. 'Árbol de la familia Musaceae (Musa paradisiaca, Musa sapientum); su fruto; homosexual, afeminado, término ofensivo': del latín platanus 'árbol de familia Plantacea', del griego plátanos 'ídem', de platanistos 'nombre de una especie específica de platanácea de Asia Menor (Platanus orientalis)', de platys 'ancho, extenso', 
en referencia a sus hojas, del PIE *plat 'extender', de *pele 'extenso, llano, plano'. El sentido de 'homosexual' se debe al empleo de este término como un eufemismo del vocablo playo 'ídem'.

Parte. 'Multa por infracción de las normas de tránsito': abreviación de la frase parte de tránsito, de parte 'escrito generalmente breve que sirve para notificar o dar aviso', del latín pars, -tis 'porción indeterminada de un todo', del PIE *per 'asignar, repartir, distribuir'.

Buzo. 'Ropa deportiva que consta de un pantalón amplio y una sudadera hechos del mismo material y color; persona que hurga en los basureros para reciclarlos': de buzo 'el que trabaja sumergido en el agua', del portugués búzio 'ídem', originalmente 'caracol que vive debajo del agua', del latín bucina 'cuerno de boyero'. El primer sentido proviene de la abreviación de la frase metafórica traje de buzo.

Pargo. 'variedad de peces de la familia Lutjanidae (Lutjanus vivanus); vagabundo, holgazán': de pargo, variante de pagro 'pez de la familia Sparidae (Pagrus pagrus)', del latín pagrus 'ídem'. Los peces de la familia Lutjanidae viven en un mar de clima subtropical asociados a los arrecifes de coral. Por su movimiento sosegado en aguas tranquilas parecen tener una lentitud semejante a la atribuida a un holgazán.

Tiricia. 'pereza, desidia, desgano': de tiricia o tericia, formas arcaicas y populares derivadas de ictericia 'enfermedad producida por acumulación de pigmentos biliares en la sangre, cuyo síntoma más visible es la amarillez de la piel', del latín medieval icteritia 'ídem', derivado del adjetivo ictericus 'quien padece esta enfermedad', del griego ikterikós 'ídem', derivado del sustantivo ikteros 'ictericia'. Se supone que la raíz ikt(er) se refiere al 'color amarillo' en griego, porque aparece en ciertos vocablos de animales que presentan esa coloración característica (iktinós 'marta', iktis 'milano'). El significado de 'pereza, desidia, desgano' proviene de la percepción tradicional de que las enfermedades hepáticas tienen como consecuencia un desgano vital.

El segundo tipo de voces agrupa a los vocablos cuyas formas no se consignan en el español estándar. Se trata sobre todo de los préstamos de otras lenguas. Desentrañar el origen etimológico de estas adopciones constituye, quizá, el reto mayor de esta empresa. Algunos ejemplos de estos casos son los siguientes:
Chante. 'Casa, hogar, local, lugar': del inglés shanty 'casucha, choza, tugurio', del francés canadiense chantier 'barraca de leñador', en francés estándar 'barraca de madera, puerto', del francés antiguo cantier 'soporte, plataforma, astillero', del latín cantherius 'viga, potro para sujetar a los caballos', originalmente 'caballo castrado, rocín, jumento, caballo de carga', del griego kanthélios 'asno'.

Estrilar. 'Reclamar, renegar': del italiano estrilare 'chillar, gritar', derivado de strillo 'grito fuerte y agudo', de la forma sincopada *strid'lo, que proviene del diminutivo stridulo 'ídem', derivado del verbo stridere 'gritar aguda y ásperamente, en especial como lo hacen los animales', del latín stridere 'ídem'.

Chinchorro. 'Casucha, tugurio': del euskera txintxor 'grava, cascote de piedra, escombros de una edificación derribada o arruinada'.

Upe. 'Interjección usada para averiguar si hay alguien en casa o en cualquier otro lugar privado': de upar (también aupar) 'levantar' y afín a la forma upa (también aúpa) 'interjección usada para esforzar a alguien a levantarse o levantar un peso', del caló gitano upre o upré (también aupré) 'arriba, encima', del PIE *upér 'sobre, encima'. En el caló también existe la forma auprar 'arribar, llegar', que tiene el mismo origen.

Cacharpa. 'Automóvil que no funciona bien o está viejo': del quechua kacharpa 'bártulos, trebejos, utensilios y ropa de poco valor y, por extensión, cosas viejas', derivado de kacharpariy 'despedir; acompañar por cortesía al que sale de viaje', derivado de kachay 'remitir, enviar'. El sentido de 'bártulos, trebejos' proviene de la idea de que el equipaje contiene los enseres de un viajero.

Ful. 'Lleno': del inglés full 'ídem', del PG *fullaz 'ídem', del PIE *pel 'llenar'.

En general, los diccionarios descriptivos que no contemplan la perspectiva etimológica enfrentan el problema de la homonimia simplemente ignorándola.

Sobre este asunto, en la introducción de su Diccionario de hispanoamericanismos no recogidos por la Real Academia, Renaud Richard expresa:

Cabe precisar al respecto que en nuestro trabajo, los homónimos no dan lugar a entradas especiales: 
el grupo prefirió no abordar las etimologías (tan inseguras y discutidas) de las formas y locuciones presentadas (p.10).

Por ello, por ejemplo, en el Diccionario de americanismos de la Asociación de Academias, el vocablo gato incluye acepciones muy distintas como definiciones del mismo lema. Véanse los sentidos con la marcación de costarriqueñismo de este término que aparecen en esta obra:

Gato. I. 1. m. Mex, CR, Ch. Juego de las tres en raya. [...] XI. 1. m. CR. Pieza de repostería compuesta de dos tapas unidas con miel o conserva.

En este caso, la pertinencia de la precisión etimológica se hace evidente.

Gato'. 'Juego que consiste en colocar equis y ceros en un cuadrado dividido en otros cuatro con sus líneas diagonales trazadas': del latín cattus 'gato silvestre', derivado de catta 'ídem', de origen incierto, pero seguramente de alguna lengua de la familia afroasiática (cf. árabe qitt 'idem')

Gato' $^{2}$ 'Variedad de repostería rectangular compuesta de dos piezas unidas por una miel o conserva': del francés gâteau 'pastel', de gastel 'masa de tarta', del fránquico antiguo *wastil 'alimento', derivado de *wahs 'cera', del PG *wakhsan 'ídem'.

Lo mismo sucede con el lema china en el Nuevo diccionario de costarriqueñismos de Quesada Pacheco, el cual corresponde a dos vocablos distintos en su origen. Sin embargo, este autor consigna las acepciones en una misma entrada.

China. f. Niñera // 2. [Bot.] Nombre de planta ornamental que da flores de diversos colores, muy común en los jardines (Impatiens wallerana).

En el diccionario etimológico, las distintas acepciones aparecerán en entradas distintas.

China'. 'Niñera': del quechua china 'hembra tanto animal como humana, hija, muchacha, sirvienta'.

China $^{2}$. 'Planta ornamental (Impatiens wallerana)': del nombre del país China, del portugués China, (usado primero en italiano por Marco Polo), del sánscrito Cìna 'chinos', seguramente del nombre de la dinastía Qin (pronunciado 'chin'), durante la cual se formó el primer imperio chino. Probablemente, esta planta fue denominada así por ser originaria de China.

Es interesante mostrar que, por otro lado, en algunas ocasiones este autor consigna en entradas distintas, palabras que provienen del mismo étimo. Esto sucede también con otros autores.

Zorra. f. Mujer que tiene amoríos con varios hombres.

Zorra. f. (Zona Noroeste) [Ict.] Cierto pez de color cenizo, picudo.

Ambas voces presentan un origen etimológico idéntico. Si se incluyera, la entrada quedaría especificada de la siguiente manera en el diccionario etimológico:

Zorra. 'Mujer de una moral sexual considerada muy liberal; especie de tiburón de la familia Lamnidae (Alopias vulpinus)': de zorra 'prostituta; mamífero cánido carnicero (Vulpes vulpes)', del portugués zorra 'holgazán', derivado del portugués antiguo zorrar 'arrastrar'. La denominación del cánido con esta palabra tenía carácter de vituperio. El nombre del animal acuático proviene de la abreviación de la frase pez zorra, llamado así debido a que la longitud de su cola, que es igual o superior al de resto de su cuerpo, recuerda la del zorro.

Finalmente, presento a continuación un último ejemplo, tomado del Nuevo diccionario de americanismos e indigenismos de Marcos Morínigo (1998), que también ilustra las complicaciones que derivan de incluir homónimos en una misma entrada. A pesar de que este diccionario incluye etimologías para ciertas voces, especialmente para muchos indigenismos, aparecen discordancias debidas al pasar por alto la homonimia. El autor define tres sentidos para el lema joco.

Joco, ca. (Del náhuatl xococ, agrio.) adj. Cen. y Méx. Agrio. Se dice de las frutas fermentadas. $\mid \mathrm{Col}$. Hueco. | Cos. Agrio en general. Se dice también del sudor y del aliento humanos.

Es evidente que la segunda acepción del término difícilmente está relacionada con los otros dos significados. El hecho de asignar la 
misma etimología para todas las acepciones resulta claramente engañoso.

En el diccionario etimológico, eventualmente, habría que establecer dos entradas distintas para estas acepciones.

Joco'. 'Agrio; fermentado, en especial la leche; hediondo': del náhuatl xokoo' 'agrio, ácido'.

$\mathbf{J o c o}^{2}$. 'Hueco (adj.)': del quechua hutk'u 'hueco, cóncavo; hueco, hoyo, agujero'.

El tercer tipo de vocablos está constituido por las palabras derivadas, que toman como base un término del español general $u$ otro costarriqueñismo. Algunos ejemplos son los siguientes:

Chichota. 'Bulto que se forma en la cabeza a causa de un golpe': derivado de la forma regresiva *chicha de chichón 'ídem', del latín abscessio, -onis 'ídem', derivado de abscessus 'tumor' (literalmente, 'separación'), derivado de abascedere 'retirarse, alejarse', de abs- 'desde'(del PIE *apo 'desde lejos') + cedere 'moverse' (del PIE *ked 'ídem') + -ota terminación de sustantivos con valor aumentativo.

Desbarrancarse. 'Caer en un despeñadero; contraer matrimonio': verbo derivado de desprefijo que indica la compleción de un evento, el latín dis- 'ídem' + barranco 'precipicio por donde puede despeñarse algo', origninalmente 'torrente profundo', de origen ibérico prerromano.

Helazón. 'Frío intenso': nombre derivado de helar, del latín gelare 'helarse, congelarse', de gelu 'hielo' + -ón terminación de sustantivos que indica el efecto o estado de un evento, del latín -ionem 'ídem'.

Desmoletado. 'Sin muelas o dientes': participio derivado de desmoletar.

Desmoletar. 'Quitar las muelas o los dientes': verbo derivado de des- prefijo de negación, del latín dis- 'ídem' + moleta 'muela pequeña', de muela 'cada uno de los dientes posteriores a los caninos', del latín mola 'piedra de moler', del PIE *mel 'frotar, moler' + -eta terminación de sustantivos con valor diminutivo, femenino de -ete 'ídem', del francés antiguo -et 'ídem', del latín -itus 'ídem'.

Fulear. 'Llenar por completo de combustible un automóvil': verbo derivado de $\boldsymbol{f u l}+\boldsymbol{e}$ sufijo de significado frecuentativo.
A manera de ilustración, es interesante señalar que, en algunos casos, la indeterminación de la homonimia llega a ser desorientadora también con los vocablos derivados. Considérese el caso del lema guapote consignado en el Diccionario de la Real Academia Española (DRAE):

Guapote, ta. (Del aum. de guapo) 1. adj. coloq. Bonachón, de buen genio. \| 2. coloq. De buen parecer. \| 3. m. C. Rica, Guat. y Nic. Pez de agua dulce, muy carnoso, de ocho a doce pulgadas de longitud.

En realidad, la tercera acepción consignada en la entrada anterior no se deriva del español guapo, sino que proviene de una lengua indígena americana.

Guapote. 'Pez de agua dulce de la familia Cichliadae (Herotilapia multiespinosa)': del náhuatl wapo-tl 'ídem', probablemente del totonaco waapa 'ídem'.

Lo mismo sucede con el lema mapachín. En el Diccionario de Americanismos de la Asociación de Academias de la Lengua Española este aparece precisado como una palabra derivada de mapache, al igual que lo es mapachito 'mapache de menor tamaño que la especie común (Procyon pygmaeus)' Sin embargo, aunque el vocablo mapachín comparte, evidentemente, la raíz con la voz mapache, no constituye una derivación del español.

Mapachín. 'Mapache (Procyon hernandezii)': del náhuatl maapáchin 'ídem'.

Probablemente, esta forma proviene de la variedad de azteca denominada nicarao que se habló en Honduras, Nicaragua y el norte de Costa Rica en la época de la conquista española, pues aparece reportada como regionalismo en estos tres países .

El cuarto tipo de voces corresponde a los calcos semánticos tomados de otras lenguas. Estos son de dos clases: extensiones de significado de una lexía ya existente por influencia de una lengua extranjera y traducciones literales de frases o lexemas pluriverbales de otra lengua.

Algunos ejemplos de esta clase son los siguientes: 
Aplicación. 'Solicitud hecha por escrito; formulario para la solicitud': calco del inglés application 'solicitud' (1851).

Parlante. 'Aparato electroacústico que sirve para amplificar el sonido': Abreviación de la frase alto parlante 'ídem', calco del inglés loudspeaker 'literalmente, alto parlante' (1884).

Concreto. 'Mezcla de piedras menudas, cemento y arena, hormigón': calco del inglés concrete 'ídem' (1834).

Celular. 'Teléfono móvil': Abreviación de la frase teléfono celular 'ídem', calco del inglés cellular phone 'literalmente, teléfono celular' (actualmente cell phone) (1977). La denominación de celular se debe a que los sistemas de servicio telefónico móvil utilizan una red de transmisores para una área de cobertura de unos cuantos kilómetros cuadrados llamado técnicamente, en los Estados Unidos, cellular network 'red de celdas, red celular'.

Patear el balde. 'Morir': calco del inglés kick the bucket 'literalmente, patear el balde: morir' (1785). El sentido de esta frase proviene de la confusión de la palabra bucket ${ }^{1}$ 'balde' (del anglonormando buquet 'tina, cuba', del inglés antiguo buc 'barriga; cántaro'), con la voz original bucket ${ }^{2}$ 'balanza' (del francés antiguo buquet "viga o yugo del cual se colgaban animales sacrificados en las carnicerías') reforzada por la idea del suicidio por ahorcamiento.

Los calcos que aparecen consignados como costarriqueñismos en los diccionarios consultados son muy escasos.

Por otro lado, el análisis de las entradas correspondientes a las letras F, L, Z, tomadas como una muestra aleatoriamente, indica que la mayor parte de los lemas corresponden al primer tipo de relación etimológica: las extensiones de significado de un término que ya existe en el español general. La proporción de este tipo corresponde al $48.3 \%$ del total.

El segundo tipo de relación etimológica: las palabras derivadas constituyen el $42,8 \%$ del total de todos los casos.

Finalmente, las voces que no aparecen consignadas en el español estándar más general corresponden al 8,9\% del total de la muestra. Este tipo de palabras está conformado por préstamos de diversas lenguas.
La mayor parte de estos vocablos son anglicismos y nahuatlismos. Sin embargo, hay voces de muy diversos orígenes. A continuación se muestran algunos ejemplos ilustrativos.

Mufla. 'Tubo de escape de los automóviles': del inglés muffler 'silenciador de automóvil', derivado de muffle 'cubrir o envolver algo para protegerlo', del francés antiguo moufle 'mitón, tipo de guante que cubre hasta el nacimiento de los dedos', del bajo latín muffula 'ídem', probablemente del fránquico antiguo *muff 'envoltura' + vël 'piel de animal'.

Tanate. 'Paquete de cosas; montón; lío, embrollo', del náhuatl tana-tl 'zurrón, espuerta hecha de tejidos de palma'.

Guaro. 'Aguardiente hecho de caña de azúcar': forma regresiva derivada de guarapo.

Guarapo. 'Jugo de caña de azúcar en proceso de fermentación': del quechua warapu 'ídem', de wiru 'caña de maíz; caña de azúcar'.

Purruja. 'Insecto díptero de la familia Psychodidae (Phebotomus papatasi)': del huetar (chibcha) purrux 'ídem', del PC *burru $+-a$ marcador de género.

Nimbuera. 'Vasija de gran tamaño usada para almacenar agua': del chorotega (otomangue) nimpu 'agua, lluvia' + -era terminación que indica pertenencia o relación, del latín -aria 'ídem'.

Acoi. 'Aquí': del caló gitano acoi 'aquí, acá', del romaní (indoario) ákaj 'aquí', de aká 'este'.

Fuete. 'Látigo': del francés fouet 'ídem' (literalmente, 'hayita', es decir, 'varilla de haya'), diminutivo del francés antiguo fou 'haya', del latín fagus 'ídem', del PIE *bhagos 'ídem'.

Kinder. 'Escuela de párvulos': abreviación de kindergarten 'ídem', del alemán Kindergarten 'ídem', literalmente 'jardín de niños', de Kind 'niño' + -er sufijo plural (del PG *kinthan 'ídem', del PIE *géntom 'ídem') + Garten 'jardín' (del alto alemán antiguo garto 'ídem', del PG *garda 'recinto, patio, jardín', del PIE *gharto- 'ídem', derivado de *gher 'agarrar, encerrar, cercar').

Fututo. 'Difícil, infortunado; atolondrado; ebrio': de fotuto 'deteriorado, dañado, perjudicado, 
enfermo', del italiano fottuto 'jodido, fastidiado', derivado de fottere 'joder, practicar el coito, perjudicar, fastidiar', del latín futuere 'practicar el coito', del PIE *bhaut 'golpear, pegar'.

Garúa. 'Llovizna': de garuja 'ídem', del portugués dialectal caruja 'niebla', del latín vulgar *calugo, -inis, en latín clásico caligo, -inis 'niebla, humo, tinieblas'.

Gungú. 'Especie de arbusto leguminoso (Cajanus cajan, Cajanus indicus)': del inglés criollo limonense gungú 'ídem', del kikongo (níger-congo) ngungu 'frijol'.

Tufí. 'Trozo de excremento sólido': del kikongo (níger-congo tufi 'excrementos'.

Esta lista de adopciones de otras lenguas es amplia y diversa. Los avatares de los medios por los cuales estas fueron incorporadas en el habla costarricense son, sin duda, tan fascinantes como intrincados. Su esclarecimiento develará las complejas relaciones y los múltiples intercambios sociales que han existido entre los hablantes en el ámbito del mundo hispanoamericano.

Baste mencionar, por el momento $\mathrm{y}$ a modo de ejemplo, que la mayor parte de los costarriqueñismos que presentan étimos procendentes del italiano, tales como los ya mencionados estrilar y fututo y otros más como birra 'cerveza', baratieri 'barato', cachar 'hurtar cosas de poco valor', cantina 'taberna', camorra 'pleito', ecolecuá 'Interjección que expresa aprobación y conformidad' y pacho 'acontecimiento divertido, irrisorio' son términos que existen igualmente, con idénticos significados, en el lunfardo rioplantense y tienen su origen en una jerga delincuencial compartida.

Así, pues, por todo lo dicho anteriormente, considero que la tarea de averiguar y esclarecer las etimologías de los vocablos del español de nuestra región, contribuirá a una mejor comprensión de nuestra propia identidad como costarricenses y centroamericanos, y nos puede ayudar también a interpretar más acabadamente cuál es nuestro lugar dentro de un mundo, sin duda alguna, compartido por todos.

\section{Bibliografía}

Agüero, Arturo. (1996). Diccionario de costarriqueñismos. San José: Asamblea Legislativa.

Alcedo, Antonio de. (1786-1789). Diccionario histórico geográfico de las Indias Occidentales ó América. Madrid: Imprenta de Manuel González.

Aleza-Izquierdo, Milagros. (2000). "Nuevos enfoques metodológicos en la práctica lexicográfica hispanoamericana diferencial actual (sobre algunos diccionarios de los 90)". En Milagros Aleza-Izquierdo \& Ángel López García (eds.) Estudios de filología, historia y cultura hispánicas. Valencia: Universitat de València.

Asociación de Academias de la Lengua Española. (2010). Diccionario de americanismos. Lima: Santillana.

Ayala, Manuel José de. 1750-1777 [1995]. Diccionario de voces americanas. Madrid: Arco Libros (edición de Miguel Ángel Quesada Pacheco).

Batres Jáuregui, Antonio. (1896). Vicios del lenguaje y provincialismos de Guatemala. Guatemala: Tipografía Nacional.

Covarrubias, Sebastián de. 1611 [1998]. Tesoro de la lengua castellana. Barcelona: Editorial Alta Fulla.

Gagini, Carlos. (1893). Diccionario de barbarismos y provincialismos. San José: Tipografía Nacional.

.1818. [2010]. Diccionario de costarriqueñismos. San José: Editorial Costa Rica. 
Gelabert, Pedro José. 1853 [1984]. Ensayo de un diccionario aragonés-castellano. Madrid: Ediciones El Museo Universal.

Nebrija, Antonio. (1492). Gramática de la lengua castellana. Edición digital. Consultado en: http://www.antoniodenebrija.org/indice. html.

Morínigo, Marcos. (1998). Nuevo diccionario de americanismos e indigenismos. Buenos Aires: Editorial Claridad.

Pichardo, Esteban. (1836). Ensayo provincial de voces cubanas. Matanzas: Imprenta de la Real Marina.

Quesada Pacheco, Miguel Ángel. (1991-2007) Nuevo diccionario de costarriqueñismos.
Cartago: Editorial Tecnológica de Costa Rica.

- (1995). Diccionario histórico del español de Costa Rica. San José: Editorial Universidad Estatal a Distancia.

Sánchez, Víctor Manuel. [en elaboración] Diccionario de costarriqueñismos.

Real Academia Española. 1726-1739 1984]. Diccionario de Autoridades. Madrid: Gredos. . (2001). Diccionario de la Real Academia Española. Madrid: Espasa.

Richard, Renaud. (1997-2006). Diccionario de hispanoamericanismos no recogidos por la Real Academia. Madrid: Cátedra. 